\title{
An approach to the computation of effective strength characteristics of porous materials
}

\author{
V. A. Levin ${ }^{1}$, I. I. Vdovichenko ${ }^{1}$, A. V. Vershinin' ${ }^{1}$, M. Ya. Yakovlev², K. M. Zingerman ${ }^{3,4, \dagger}$ \\ †zingerman@rambler.ru
}

\author{
${ }^{1}$ Lomonosov Moscow State University, Leninskiye Gory, 1, GSP-1, Moscow, 119991, Russia \\ ${ }^{2}$ Fidesys LLC, Office 402, 1 bld. 77, MSU Science Park, Leninskie Gory, Moscow, 119234, Russia \\ ${ }^{3}$ Tver State University, Zhelyabov st., 33, Tver, 170100, Russia \\ ${ }^{4}$ National Research Nuclear University MEPhI, Kashirskoe shosse, 31, Moscow, 115409, Russia
}

An approach to the computation of effective strength characteristics of porous materials is developed. The approach is implemented for 2D problems (plane strain) within the scope of linear elasticity. The approach can be generalized for 3D problems and nonlinear elasticity. The specific features of the proposed approach are as follows. First, a representative area of material which contains pores is specified. A series of boundary-value problems is solved under periodical boundary conditions for different types of deformation of the external boundary. The finite element method is used for solution. Averaging of stresses is performed for each problem, and the principal values of averaged stresses are computed. The maximal value of the stress intensity over the representative area is then calculated. Finally, principal values of stresses at which fracture occurs are computed. By this way, a point on a plane of principal stresses is determined, which corresponds to the specified boundaryvalue problem. A set of such points is formed for the series of boundary-value problems, and the boundary points of this set are determined. The obtained set of boundary points is approximated by a polygonal line. The parameters of segments of this polygonal line are computed. This computation allows one to obtain a macroscopic strength criterion in an analytical form. The obtained relations can be further reduced to the form of the Mohr-Coulomb criterion. The numerical results are given in the paper for a particular case in which the representative area is a square containing a centered elliptical hole.

Keywords: effective strength, porous material, strength criterion.

\section{Introduction}

The computation of effective strength of inhomogeneous materials is an important problem of micromechanics. The solution of this problem is important for the improvement of mechanical properties of materials by means of microstructure controlling [1]. The essence of this problem is to determine the strength characteristics of materials at the macrolevel by given properties and structure of these materials at the microlevel. Different approaches to the solution of this problem are developed, for example, in [2-9].

The backbone of the idea of effective strength estimation is as follows. A representative region of a material is considered (volume in $3 \mathrm{D}$ case, area in $2 \mathrm{D}$ case). Stresses are applied to this volume, and inhomogeneous stress state is induced by these stresses. A "local" strength (fracture) criterion is prescribed; this criterion prescribes fracture at a point of this volume. It is assumed that the representative volume (area) is fractured "as a whole" provided that the fracture criterion is satisfied at some point of this volume.

The widespread approach to the estimation of effective strength is based on analytical solutions of linear elasticity problems and stress concentration tensor [2,3]. However, there are some limitations on this approach. These limitations are related, in particular, to the fact that analytical solutions for regions containing interacting holes and for periodical arrangement of holes are tedious.

The paper presents an approach to the computation of effective strength characteristics on the base of finite-element analysis. The proposed approach is based on the solution of a sequence of elasticity boundary-value problems for a representative volume (area) for different types and values of average strains of this volume (area). As a result, a set of points of fracture surface is formed in the space of principal stresses. Using these points, one can approximate the fracture surface analytically. As a result, the strength criterion is obtained in an analytical form.

\section{Methodology}

The approach to the computation of effective strength characteristics is described for the $2 \mathrm{D}$ case (the case of plane strain). The sequence of doubly periodic boundary-value problems of elasticity theory is solved under given average strains 


$$
\mathbf{E}=\left(\begin{array}{ccc}
\alpha \delta & \gamma \delta & 0 \\
\gamma \delta & \beta \delta & 0 \\
0 & 0 & 0
\end{array}\right) .
$$

Here $\delta$ is a constant, $\alpha, \beta$ and $\gamma$ are parameters that vary within limits $\alpha_{\text {min }} \leq \alpha \leq \alpha_{\text {max }}, \beta_{\text {min }} \leq \beta \leq \beta_{\text {max }}, \gamma_{\text {min }} \leq \gamma \leq \gamma_{\max }$ by prescribed steps $h_{\alpha}, h_{\beta}, h_{\gamma}$, respectively. The finite-element method is used for solution. This method is implemented in the Fidesys CAE-system [10]. The specific features of the meshing algorithm for the case in which periodic boundary conditions are imposed are described in [11].

The averaging of the stress tensor $\boldsymbol{\sigma}$ is performed for each boundary-value problem of elasticity theory (for the given values of parameters $\alpha, \beta$, and $\gamma$ in the expression for the strain tensor $\mathbf{E}$ ). For this, the following relation is used [12-14]

$$
\langle\boldsymbol{\sigma}\rangle=1 / S \iint_{S} \boldsymbol{\sigma} \mathrm{d} S=1 / S \oint_{\Gamma} \mathbf{N} \cdot \boldsymbol{\sigma} \mathbf{R} \mathrm{d} S,
$$

where $S$ is a representative area, $\Gamma$ is the external boundary of $S, \mathbf{N}$ is the unit normal to this boundary, and $\mathbf{R}$ is the radius vector of a point of this boundary. Then the maximal stress intensity over the representative area is determined for the considered problem:

$$
\sigma_{i}=\frac{1}{\sqrt{2}} \sqrt{\left(\sigma_{11}-\sigma_{22}\right)^{2}+\left(\sigma_{22}-\sigma_{33}\right)^{2}+\left(\sigma_{33}-\sigma_{11}\right)^{2}+6\left(\sigma_{12}^{2}+\sigma_{23}^{2}+\sigma_{13}^{2}\right)^{2}} .
$$

At the next step, the principal values of the averaged stress tensor $\langle\boldsymbol{\sigma}\rangle$ in the plane of strain are computed. These values are further denoted by $\sigma_{1}$ and $\sigma_{2}$.

Assume that the local fracture criterion at the micro-level has a form $\sigma_{i} \geq \sigma^{\star}$, where $\sigma^{*}$ is a prescribed value. Assume additionally that it is sufficient for fracture of a representative area at the macro-level if the local fracture criterion is satisfied at least at a point of this area. Within the scope of linear elasticity and small strain theory, the limiting principal values $\sigma_{1}^{c r}$ and $\sigma_{2}^{c r}$ of average stress tensor $\langle\boldsymbol{\sigma}\rangle$ can be computed by formulas

$$
\sigma_{1}^{c r}=\sigma_{1} \sigma_{\sigma_{i}}^{*}, \quad \sigma_{2}^{c r}=\sigma_{2} \sigma^{*} \sigma_{i} .
$$

These limiting values correspond to the fracture of a representative area at the macro-level.

The set of points $\left(\sigma_{1}^{c r}, \sigma_{2}^{c r}\right)$ in the plane of principal stresses

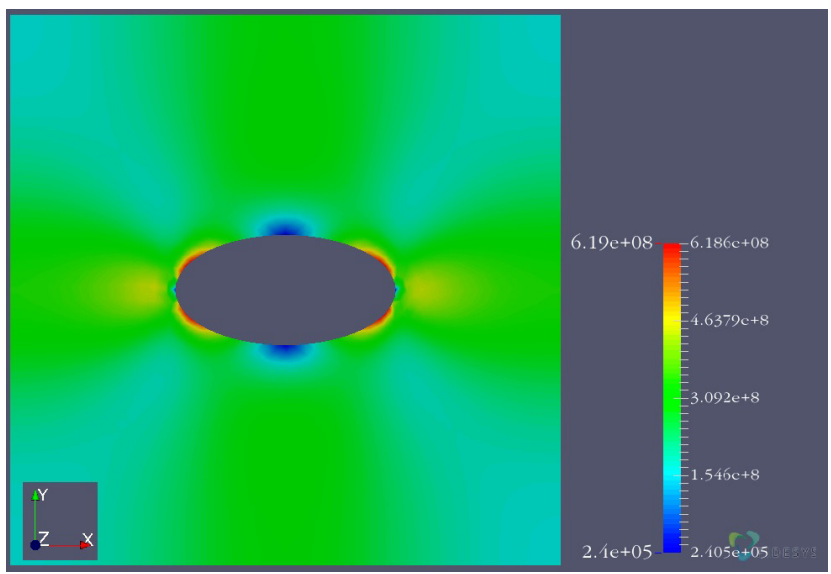

Fig. 1. (Color online) The distribution of stress intensity in the representative area for a particular case. is formed as a result of solving the sequence of boundaryvalue problems.

The following approach is used in order to extract boundary points from this set of points and to obtain the strength criterion in analytical form. The plane of principal stresses is divided onto $M$ equal sectors ( $M$ is a sufficiently large integer) by rays emerging from the origin. A point that is nearest to the origin is chosen in each sector. The obtained set of points is the desired set of boundary points. At the next step, the set of points is approximated by an analytical relation between the principal stresses $\sigma_{1}$ and $\sigma_{2}$ (the method of least squares can be used for this purpose). As a result, the effective strength criterion is obtained in analytical form.

\section{Results of computations}

The computations are performed for a particular case in which the representative area is a square containing a centered elliptical hole. The semi-axes of the ellipse are equal to $a=0.2 l, b=0.1 l$, where $l$ is the square side. The following values of parameters are used: $\delta=0.02$; the parameters $\alpha, \beta$, and $\gamma$ range from -1 to 1 by the step of 0.1 . The material properties are described by Hooke's law with the Poisson ratio $v=0.25$. The example results of stress analysis of a representative area are given in Fig. 1.

The set of points $\left(\sigma_{1}^{c r}, \sigma_{2}^{c r}\right)$ in the plane of principal stresses is given in Fig. 2. This set of points is obtained as a result of computations. The stresses are referred to the value of $\sigma^{*}$.

The set of boundary points is shown in Fig. 3. This set is obtained by processing of the data that are shown in Fig. 2 .

One can see from Fig. 3 that the set of boundary points can be approximated by a polygonal line. This line consists of four segments. The approximation results in the following relations:

$$
\sigma_{2}=0.1753 \sigma_{1} \pm 0.2 \sigma^{*} ; \quad \sigma_{1}=0.171 \sigma_{2} \pm 0.2 \sigma^{\star} .
$$

One can see that the coefficients of these two relations are approximately the same. So, the set of boundary points is well approximated by a rhombus centered in the origin. The obtained relations can be reduced to the form of MohrCoulomb stress criterion [15].

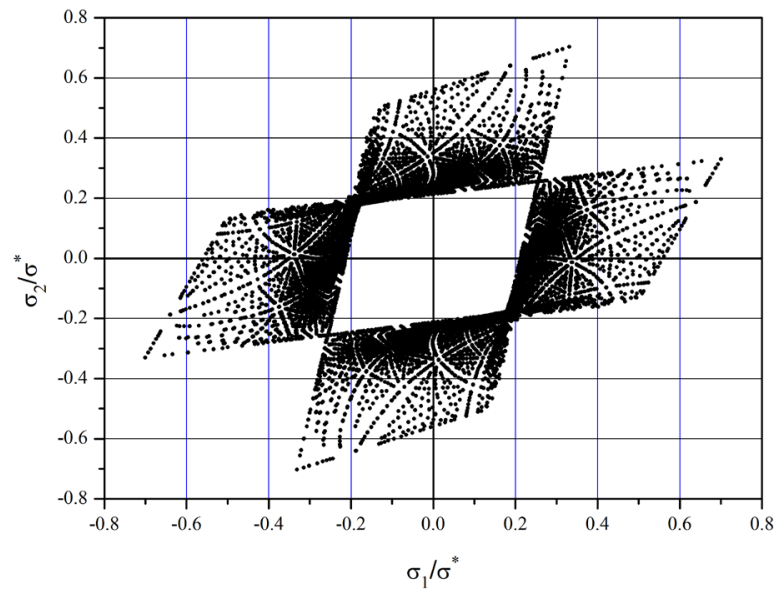

Fig. 2. The set of points in the plane of principal stresses. 


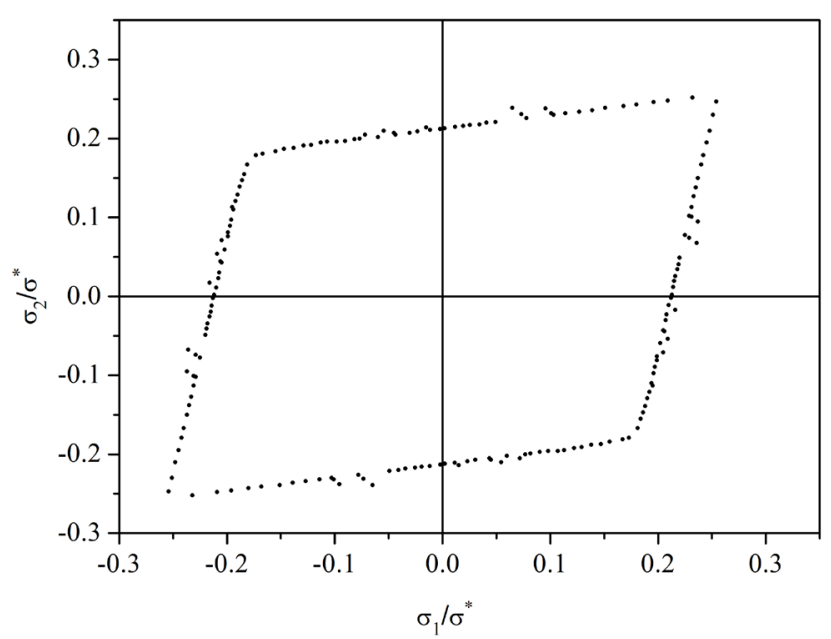

Fig. 3. The set of boundary points in the plane of principal stresses.

\section{Conclusions}

As the result, the paper gives an approach for the computation of effective strength characteristics of porous elastic media. The developed approach is intended for numerical solution of a series of elasticity problems for a representative volume (area) of a medium. The finite-element computations are performed, and the analytical expressions for the strength criterion are obtained.

In addition, the proposed approach can be used for the estimation of effective strength of composite materials [12] and core samples. One can extend this approach to the nonlinear problems under finite strains. The computations in this case are more time consuming when compared with linear elasticity, because in the nonlinear problems the stress analysis should be performed for some values of the parameter $\delta$.

Acknowledgements. This work was financially supported by the Ministry of Education and Science of the Russian Federation in the framework of the agreement No. 14.579.21.0112 (unique identifier of the project RFMEFI57915X0112). Investigations were carried out within the Fidesys company - a grantee of the Ministry of Education and Science of the Russian Federation.

\section{References}

1. T. I. Nazarova, V. M. Imaev, R. M. Imaev, R. R. Mulyukov. The Physics of Metals and Metallography. 117 (10),
1038 - 1046 (2016), DOI: 10.1134/S0031918X16080111.

2. I.F. Obraztsov, A.N. Vlasov, Yu. G. Yanovsky. Doklady Physics, 51 (1), 44-47 (2006), DOI: 10.1134/ S1028335806010113.

3. A. N. Vlasov, V. P. Merzlyakov, S. B. Ukhov. Soil Mechanics and Foundation Engineering, 40 (6), 197 - 205 (2003).

4. I. Sevostianov, M. Kachanov. Int. J. Fract. 164, $147-154$ (2010), DOI: 10.1007/s10704-010-9485-6.

5. M. N. Bidgoli, Z. Zhao, L. Jing. Journal of Rock Mechanics and Geotechnical Engineering 5, $419-430$ (2013). DOI: 10.1016/j.jrmge.2013.09.002.

6. R.F. Miftakhov, A.V. Myasnikov, A.V. Vershinin, S. S. Chugunov, K. M. Zingerman. Seismic Technologies. 4, $97-108$ (2015) DOI:10.18303/1813-4254-2015-4-9 7-108 (in Russian). [Р.Ф. Мифтахов, А.В. Мясников, А.В. Вершинин, С. С. Чугунов, К.М. Зингерман. Технологии сейсморазведки, 4, 97 - 108 (2015)].

7. R.V. Goldstein, N.M. Osipenko. Physical Mesomechanics. 18 (2), 139 - 148 (2015), DOI: 10.1134/ S102995991502006X.

8. G. Bruno, M. Kachanov. J. Am. Ceram. Soc., 99 (12), 3829 - 3852 (2016). DOI: 10.1111/jace.14624.

9. E.A. Podolskaya, A. Yu. Panchenko, A.B. Freidin, A. M. Krivtsov. Acta Mechanica, 227 (1), 185-201 (2016).

10. E. M. Morozov, V.A. Levin, A. V. Vershinin. Strength analysis: Fidesys in hands of an engineer. Moscow, LENAND. (2015) 408 p. (in Russian) [E. М. Морозов, В.А. Левин, А.В. Вершинин. Прочностной анализ. Фидесис в руках инженера. М.: ЛЕНАНД, 2015. 408 c.]

11. V.A. Levin, I.I. Vdovichenko, M.Ya. Yakovlev, A.V. Vershinin, K.M. Zingerman. Modelling and Simulation in Engineering. 2016, Article ID 9010576, 10 pages (2016), DOI: 10.1155/2016/9010576.

12. B. Ye. Pobedria. Mechanics of composite materials. Moscow: MSU. (1984) 336 p. (in Russian) [Б. Е. Победря. Механика композиционных материалов. М.: Издво МГУ, 1984. - 336 с.]

13. V.A. Levin, K.M. Zingerman, A.V. Vershinin, M. Ya. Yakovlev. Composite Structures. 131, 25-36 (2015), DOI: 10.1016/j.compstruct.2015.04.037.

14. A.V. Vershinin, V.A. Levin, K.M. Zingerman, A.M. Sboychakov, M. Ya. Yakovlev. Advances in Engineering Software. 86, 80 - 84 (2015), DOI: 10.1016/j. advengsoft.2015.04.007.

15. C. A. Coulomb. Mem. Acad. Roy. Div. Sav., 7, 343-387 (1776). 